\title{
A intervenção contemporânea no patrimônio arquitetônico e a indústria cultural*
}

\author{
Ana Cristina Csepcsényi, \\ Rosina Trevisan Martins Ribeiro**
}

\begin{abstract}
Resumo A industrialização da cultura é um fenômeno que tem várias repercussões, inclusive no processo de intervenção contemporânea no patrimônio arquitetônico. Mas, até que ponto a intervenção mobilizada pelos interesses da indústria cultural pode comprometer o bem? Tendo como premissa a preservação desse patrimônio na qualidade de referência histórica, o objetivo deste artigo é estabelecer um parâmetro que pode definir tal comprometimento nessa conjuntura. Por meio de revisão bibliográfica, conclui-se que o discurso que prevalece com a intervenção (o da preexistência ou um novo discurso que a subjuga) pode conferir se houve o comprometimento do bem como referência histórica.
\end{abstract}

Palavras-chave: intervenção, indústria cultural, patrimônio arquitetônico.

\section{La intervención contemporánea en el patri- monio arquitectónico y la industria cultural}

Resumen La industrialización de la cultura es un fenómeno con varias repercusiones, incluso durante el proceso de intervención contemporánea en el patrimonio arquitectónico. Pero ¿hasta qué punto la intervención movilizada por los intereses de la industria cultural puede poner en riesgo el bien? Teniendo como premisa la preservación de ese patrimonio en cuanto referencia histórica, el objetivo de este artículo es establecer un parámetro capaz de definir tal riesgo en esa coyuntura. Por medio de revisión bibliográfica, se concluye que el discurso que prevalece con la intervención (el discurso de la preexistencia o un nuevo discurso que la subyugue) puede conferir si el bien, como referencia histórica, ha sido puesto en riesgo.

Palabras clave: intervención, industria cultural, patrimonio arquitectónico.

\section{Contemporary intervention in architectural heritage and the cultural industry}

\begin{abstract}
Industrialization of culture is a phenomenon with several repercussions, as in the process of contemporary intervention in the architectural heritage. But to what extent can the intervention provoked by the interests of the cultural industry jeopardize the asset? Assuming the preservation of this heritage as a historical reference, this article aims to establish a parameter that can define such commitment in this conjuncture. Through a bibliographical review, the conclusion was that the discourse that prevails with the intervention (about the preexistence or a new discourse that subjugates it) can assess if the asset was jeopardized as a historical reference or not.
\end{abstract}

Keywords: intervention, cultural industry, architectural heritage. 
* O presente artigo representa parte da Tese de Doutorado em desenvolvimento, com apoio da Fundação Carlos Chagas Filho de Amparo à Pesquisa do Estado do Rio de Janeiro (FAPERJ) e, antes desse, com o apoio da Coordenação de Aperfeiçoamento de Pessoal de Nível Superior - Brasil (CAPES) - Código de Financiamento 001.

** Ana Cristina Csepcsényi é Arquiteta e Urbanista, Doutoranda em Arquitetura pela Universidade Federal do Rio de Janeiro (UFRJ), ORCID <https://orcid.org/0000-00017748-8866>. Rosina Trevisan Martins Ribeiro é Arquiteta, Professora do quadro permanente do PROARQ - Programa de Pósgraduação em Arquitetura da UFRJ e do Mestrado Profissional em Projeto e Patrimônio do PROARQ/UFRJ, ORCID <https://orcid. org/0000-0001-5578-7419>. industrialização da cultura é um fenômeno contemporâneo com associações nos campos político-econômicos e socioculturais. Nessa conjuntura, a indústria cultural estrutura-se como força de mercado. O fetichismo pelo consumo cultural se propaga em escala mundial, utilizando a imagem como um recurso atrativo de impacto. No âmbito do consumo do espaço, a indústria cultural agencia a preservação do patrimônio cultural por meio do turismo cultural, mais estruturado em experiências entre as pessoas e o bem, e menos no monumento isolado. É um processo de industrialização da preservação do patrimônio que também tem o potencial de promover desenvolvimento social e econômico. E que, por sua vez, afeta a intervenção no patrimônio edificado imprimindo-lhe características peculiares, que levam a questionar: até que ponto a intervenção contemporânea no patrimônio arquitetônico, nesse panorama, pode comprometer a preservação do bem? Essa é uma discussão que tem várias vertentes. Uma delas é o comprometimento do patrimônio (representado aqui pela edificação, não pelo conjunto urbano) na condição de referência histórica. Sob esta ótica, o objetivo deste artigo é estabelecer um parâmetro que possa definir tal comprometimento da intervenção mobilizada pela indústria cultural. Essa abordagem se justifica por discutir o distanciamento entre a teoria do campo disciplinar de restauração (que deve orientar majoritariamente a intervenção) e a prática contemporânea da intervenção nesse panorama.

Por meio da revisão bibliográfica define-se o panorama contemporâneo no qual ocorre a intervenção no patrimônio arquitetônico (no que se refere à globalização e à industrialização da cultura); caracteriza-se o processo contemporâneo de definição da intervenção no patrimônio arquitetônico; e se estabelece a influência da indústria cultural nas intervenções contemporâneas, também na realidade nacional.

Com base nisso, conclui-se que o discurso que prevalece na intervenção contemporânea é o que confere se houve o comprometimento do patrimônio arquitetônico na qualidade de referência histórica. No caso, a intervenção que produz um novo discurso que subjuga o discurso da preexistência é incoerente em relação ao seu processo metodológico de desenvolvimento estabelecido no campo disciplinar teórico da restauração, comprometendo-a como referência histórica. Por sua vez, esse novo discurso é típico da ação condicionada pela indústria cultural, que fomenta e consolida o distanciamento entre o campo disciplinar teórico e a prática da intervenção, à medida que se afasta da significação dos grupos locais/regionais que deve ser a base do processo metodológico da intervenção.

Essa discussão contribui para reforçar o impacto da indústria cultural na intervenção contemporânea no patrimônio arquitetônico, em meio aos processos de hibridação cultural e em relação à assertividade quanto ao referencial conceitual teórico do campo disciplinar da restauração. 


\section{Industrialização da cultura e preservação do patrimônio}

A globalização é um fenômeno identificado principalmente pela integração. Néstor García Canclini (2007) afirma que na conjuntura da globalização, ocorrem mudanças sociais que resultam das novas relações da sociedade com o diferente, promovidas pela rapidez das comunicações e dos deslocamentos. As interações culturais perpassam fronteiras políticas, pois são fundamentadas em "[...] novos fluxos e estruturas de interconexão supranacional." A consequência disso é a alteração do "modo de fazer cultura", que implica no irreversível processo de "reorganização mundializada das sociedades" e na "interculturalidade transnacional". (CANCLINI, 2007, p. 58-59). Ou como Boaventura Santos (2002, p. 49) chama, a "universalização e a eliminação das fronteiras nacionais".

Entretanto, Canclini (2007, p. 44-45), assim como Boaventura Santos (2002), ressalta que a globalização não é uniformização. Ela é um fenômeno que associa "[...] processos de homogeneização e, ao mesmo tempo, de fragmentação articulada do mundo, que reordenam as diferenças e as desigualdades sem suprimi-las." Sendo assim, o reconhecimento da "interculturalidade transnacional" que ocorre com a globalização passa pelo entendimento de que a cultura da sociedade não é necessariamente singular em seus grupos, nem unificada. Em função disso, não cabe mais se estudar a cultura quanto "apenas a diferença, mas também a hibridação". Esse é o desafio contemporâneo mais básico para Canclini (2010, p. 131).

No âmbito da cultura transnacional, Fredric Jameson (2000, p. 28) observa a produção cultural da contemporaneidade como um processo integrado, mas sobretudo, estabelecido por meio de estruturas de poder e de condicionamento, cujas repercussões não podem ser ignoradas. $O$ autor destaca que, nessa conjuntura, a cultura adquire uma nova concepção ampliada, conferida pelo "populismo estético" que se estabelece como critério para produção. A cultura para consumo (mercado) é a de massa, que emprega a imagem como um fragmento do presente, progressivamente substituindo o produto. A imagem é propagada pela mídia, viabilizada pelas novas tecnologias e comunicações. Signos do irreal, um "pastiche", que é um "simulacro" do comportamento social e cultural que pretende a experiência da igualdade celebrando a liberdade da autorreprodução da sociedade de mídia - sociedade de consumo. E é na suposta liberdade de escolha que está a relação "simbiótica" do mercado da cultura com a mídia. A liberdade e a igualdade são almejadas, mas não se pode obtê-las como a experiência de escolha dentro de um universo de imagens pré-determinadas. O mercado raramente tem algo a ver com liberdade de escolha. (JAMESON, 2000, p. 279).

David Harvey $(2008$, p. 56) reforça que os instrumentos de manutenção desse processo produtivo são as novas tecnologias e comunicações. Elas produzem a necessidade e o desejo do consumo da cultura por meio de imagens e signos desenvolvidos para o instantâneo e constante impacto. Em função disso, esses são efêmeros e fragmentados pela descontinuidade, propiciando um "[...] modo particular de experimentar, interpretar e ser no mundo". A consequência disso para a cultura é a falta de profundidade e, por vezes, de rigor teórico.

Harvey (2008, p. 269), tal como Fredric Jameson (2000), destaca que a indústria cultural é uma força produtiva inata à sociedade. Segundo ele, a cultura produz "códigos de 
valores e significados sociais", por sua vez, o capital e as mercadorias também são "portadores primários de códigos culturais", pois o processo de circulação desses (o comércio) é uma prática cultural, mesmo que essas mercadorias sejam "mercadorias especiais ou mesmo sistemas de signos".

Ainda no contexto dos processos de industrialização da cultura, Sharon Zukin (2000, p. 96) acrescenta outra característica desse consumo, a do espaço. "A circulação de imagens para consumo visual é inseparável das estruturas centralizadas do poder econômico." Sendo assim, essas têm a capacidade de "imprimir perspectivas múltiplas", inclusive sobre a paisagem. A autora destaca que as paisagens recentes são modificadas para consumo imagético, e as paisagens históricas também têm forte apelo para esse consumo.

A industrialização da cultura engloba a preservação do patrimônio cultural no processo produtivo da indústria do turismo cultural. Nessa dinâmica, José Reginaldo Gonçalves (2007, p. 240) afirma que o patrimônio é, ao mesmo tempo, condição e efeito da industrialização da cultura na preservação, pois um não existiria sem o outro na contemporaneidade. Para o autor, o interesse particular da indústria do turismo cultural, "[...] embora representado tendencialmente de forma negativa e destrutiva, parece ser, na verdade, uma das fontes para a existência social e cultural do patrimônio."

De maneira semelhante, Ulpiano Meneses (2009, p. 38) sustenta que o valor cultural de um bem não se opõe ao valor econômico desse. Segundo ele, "[...] não há qualquer antagonismo. Há uma dimensão econômica no bem cultural, assim como uma dimensão cultural no bem econômico." Sendo assim, e também de acordo com David Harvey (2008, p. 269), o patrimônio cultural e, por sua vez, o patrimônio arquitetônico, se enquadrariam no que seriam "mercadorias especiais" desse processo produtivo.

Ignasi de Solà-Morales (1998, p. 8), ressalta que a indústria do turismo cultural se estrutura em práticas que são decisivas para as relações que se estabelecem entre o patrimônio e as pessoas. Ela promove experiências que são prefiguradas na forma como se vê e como se aprecia a arquitetura histórica. Antes, a indústria do turismo patrimonial promovia uma visão centrada nos monumentos, porém, na atualidade, existe um novo modo de ver o patrimônio como conjunto de experiências culturais (comida, música, paisagens, etc.). A "multiplicação de olhares" para a "multiplicação da circulação de imagens".

\section{Homogeneização e diversidade cultural}

Com efeito, a globalização e a industrialização da cultura conformam o panorama contemporâneo da produção cultural. Em meio às interações culturais, o consumo cultural é um modo de fazer e assimilar cultura, mas esse não é o único. A produção cultural como manifestação do próprio, do local e da diversidade, perdura. Todavia, Carlos Fortuna e Augusto Silva (2002) afirmam que o processo produtivo da indústria cultural tem por base a hegemonização da produção e do consumo em grande escala. A indústria cultural é uma força singular do sistema de produção que se estrutura incorporando "elementos culturais e simbólicos na sua cadeia de valor". Assim, ela é responsável por ações que provocam a "[...] transformação de uma realidade 'local' numa presença planetária." (FORTUNA; SILVA, 2002, p. 437-439). Nessa condição, a 
realidade local é modificada, perde características que eram sua fonte de atração - a diversidade - e ganha características globais - homogêneas -, pertinentes aos interesses da indústria e, portanto, ao seu sistema de produção. No entanto,

[...] ao mesmo tempo em que contraria a diversidade cultural quando vista do lado da oferta, não deixa também de pô-la em evidência, quando vista do lado da procura. Não se trata seguramente de um paradoxo. Mas trata-se, isso sim, de um importante elemento de tensão. (FORTUNA; SILVA, 2002, p. 437)

Um elemento de tensão ou um paradoxo, a diversidade é o ponto de atração do "empreendimento" cultural, é o início do processo de industrialização cuja consequência frequentemente é a homogeneização, conformando um fluxo cíclico. Pode-se então aventar que essa é uma ambivalência congênita do processo produtivo da indústria cultural, que tem consequências para a preservação do patrimônio arquitetônico.

Contudo, Fortuna e Silva (2002, p. 438-439) são contundentes em refutar a teoria de que a expansão da indústria cultural resultaria na "modelagem das mentes" e em "comportamentos padronizados". Segundo os autores, "[...] nem a influência sobre os receptores é tão automática, nem o resultado da interseção dessa influência com a ação dos receptores é tão uniforme." A pressão para homogeneização decorrente da hegemonia da indústria cultural é um fator de redução da diversidade, "mas não a anula imediatamente." Isto porque, "[...] a integração dos grupos sociais no sistema de produção cultural mundial traz consigo (dada a riqueza cultural que informa os grupos e dada a não passividade dos receptores) forças de heterogeneização."

Logo, a assertividade dos receptores assume a função de força de heterogeneização, que acaba por resguardar a diversidade. Contudo, cabe salientar que a "não passividade dos receptores" é uma qualidade de grupos sociais que depende de muitas variáveis, como condições socioculturais, educação, condição de expressão, etc.

A premissa da "não passividade" frente aos processos de interculturação também é discutida por Boaventura de Souza Santos (2001). O autor se baseia no reconhecimento de que há configurações culturais que podem ser identificadas como, "[...] transnacionais ou cujas origens nacionais são relativamente irrelevantes pelo fato de circularem pelo mundo, mais ou menos desenraizadas das culturas nacionais." (SANTOS, 2002, p. 46-47). "As práticas sociais hoje são simultaneamente globais e locais. É preciso amplificar a inteligibilidade entre as diferentes práticas, [...]." (SANTOS, 2001, p. 1819). Todavia, para isso, é preciso buscar o que "temos direito" sendo "[...] a voz ante os silenciamentos, que o nosso sistema social/político/econômico cria." (SANTOS, 2001, p. 18-19).

Dizem até que a luta pelo multiculturalismo e pela diversidade é o prêmio de consolação para quem perdeu a luta pela igualdade. É preciso afirmar que nas novas lutas se procura o equilíbrio forte, tenso, dinâmico, entre o princípio da igualdade, o princípio da liberdade e o princípio da diferença, e que apesar de vivermos em sociedades muito desiguais, a igualdade não nos basta, queremos ser iguais e queremos ser diferentes. (SANTOS, 2001, p. 22-23) 
Ou seja, para o autor a cultura na atualidade é, em parte, transnacional. E a condição para ser "diferente" nesse processo é antes ser "igual". A igualdade de condições estruturais é o instrumento que permite a negociação da diferença. Por conseguinte, para se resguardar a diversidade cultural na preservação do patrimônio arquitetônico, em meio ao processo de assimilação pela indústria cultural, é preciso que exista certa paridade de condições socioculturais e também econômicas entre os grupos sociais que se relacionam com o bem. Assim, permanecendo acentuadas as disparidades, a afirmação do regional/local frente às ações homogeneizantes promovidas pela indústria cultural, acaba por ser resumida pelo antagonismo entre o local e o global, o qual no fim, acaba por ser entre o econômico e o cultural; no lugar do que deveria ser primordialmente uma questão sociocultural de interlocução e negociação entre as igualdades e as diferenças.

Canclini (2007, p. 22), assim como Fortuna e Silva (2002), reafirma que a industrialização da cultura contemporânea "[...] desestrutura a produção cultural endógena, favorece a expansão de indústrias culturais com capacidade de homogeneizar e ao mesmo tempo contemplar de forma articulada as diversidades setoriais e regionais." Em face disso, o autor promove uma reflexão particular quando assegura que as "culturas periféricas" têm duas possibilidades frente à indústria cultural: "se encapsularem em suas relações locais" ou "estilizar-se" e difundir-se por meio de "empresas transnacionais". Com base nessa afirmação, "encapsular-se" significa manter as características locais, protegendo o bem dos interesses da indústria cultural, ou seja, evitar práticas que visam o consumo cultural rápido e superficial. O resultado de tal condição pode também ser estagnação econômica, haja vista que o potencial desenvolvimento promovido pela indústria fica dificultado. A outra possibilidade seria "estilizar-se", o que significa homogeneizar-se, ou seja, assumir características comuns às práticas que visam o consumo, que podem diminuir as características locais.

Entretanto, Canclini (2007, p. 115), assim como Fortuna e Silva (2002) e Santos (2001, 2002), também reforça que não há uma homogeneização cultural absoluta. "Para além das narrativas fáceis da homogeneização absoluta e da resistência do local, a globalização nos defronta à possibilidade de apreender fragmentos, nunca a totalidade de outras culturas [...]."

Em razão desses "paradoxos", Canclini (2007, p. 28-29) enfatiza a necessidade de novas práticas culturais que visam a heterogeneidade e a diferença. Para o autor, "[...] em meio às tendências globalizadoras, os atores sociais podem estabelecer novas interconexões entre culturas e circuitos que potencializem as iniciativas sociais." Dessa forma, criando "novos espaços de intermediação intercultural" e de estímulo à diversidade.

Com base nessas reflexões, compreende-se que as características locais peculiares do patrimônio arquitetônico são o foco do interesse da indústria cultural, e a preservação que é orientada por seus interesses emprega instrumentos para o consumo com potencial homogeneizante. Em contrapartida, cabe ressaltar que não há uma assimilação no patrimônio arquitetônico completamente homogeneizante e global, assim como não há um patrimônio cultural que tenha vocação exclusiva para apreciação local. Por conseguinte, a classificação espacial global $X$ local, ou mesmo a rotulagem cultura homogênea X cultura diversa (plural), não é absoluta. Esses limites são diferenças fluidas, 
1 Essa reflexão gera discussão no tocante às tendências teóricas mais contemporâneas. A "Conservação Pura" é uma das atuais derivações do "Restauro Crítico" e estabelece que o novo na intervenção de preservação do patrimônio é separado da ação de restauração. que podem vir a ser negociadas pelos grupos sociais, desde que se tenha igualdade de condições para isso, conforme Santos (2001), e desde que se tenha espaço para o reconhecimento dessas interações, conforme Canclini (2007).

\section{Intervenção contemporânea no patrimônio arquitetônico}

Para definir o entendimento do que é a intervenção no patrimônio arquitetônico, é oportuno abordar um conceito contíguo, o de restauração. Na Carta de Veneza (1964), um documento emblemático para a preservação, a ação de restauração do bem é descrita no artigo $9^{\circ}$ como uma operação indispensável e excepcional. Ela deve assegurar a compreensão do patrimônio como um documento, ser precedida de estudos sobre o bem e seguida de conjecturas, cujo limite é a hipótese.

Salvador Viñas (2003, p. 23-24, tradução nossa) atualiza essa compreensão e afirma que a "Restauração" contemporânea abarca um conjunto de ações mais amplo, que inclui a "restauração" propriamente dita. Da mesma forma que Viñas, Giovanni Carbonara (1998) ressalta que o restauro não se limita às operações para preservação da materialidade do bem, haja vista que ele também abarca operações necessárias ao uso e à funcionalidade da edificação. ${ }^{1}$

Em razão disso, Viñas (2003, p. 35, tradução nossa) afirma que a amplitude contemporânea do conceito "[...] representa um problema substancial ao tentar entender a Restauração como disciplina." Para se evitar esse problema, tem-se assumido tacitamente que existem "bens que têm maior interesse cultural do que outros", e para estes, caberia o rigor técnico da restauração. Este é um entendimento equivocado, segundo Carbonara (1998). Para o autor, tal crença só teria valia se o valor econômico do bem fosse preponderante na preservação, não o valor cultural. Outrossim, o valor mercantil (econômico) da arquitetura histórica não deve definir a operação no patrimônio, porque ele impõe decisões à intervenção que não visam prioritariamente a preservação do bem.

Nesse contexto, Carbonara (2012, p. 4-5, tradução nossa) sustenta que restauro significa, "[...] primeiro e acima de tudo, um trabalho direto em um objeto e até mesmo uma mudança de uma objeto, sempre sob rigorosa análise técnico-científica, histórica e crítica [...]." Esse trabalho é um evento traumático para qualquer patrimônio, e, ao empreendê-lo, não se deve conduzir tal operação como outra coisa que não seja efetivamente uma ação de restauro. Ou seja, a iniciativa deve ser comprometida com o rigor técnico pertinente ao campo teórico da restauração. Segundo o autor, qualquer outra operação que vá além do restauro, comumente estabelece "um novo e diferente exercício de design", um novo desenho à preexistência. Sendo assim, a historicidade do patrimônio se reduz a um "simples fundo, uma espécie de citação da antiguidade". Beatriz Kühl (2008, p. 207) acrescenta que essas operações "[...] refletem posturas conceituais inadequadas, pois se afastam das razões que motivaram a preservação e procuram distanciar-se do conceito de restauro [...]."

Com base nesses autores, se assume que qualquer ação no patrimônio cultural, independentemente da importância desse, deve mirar o restauro de modo a resguardar o valor cultural do bem com a preservação. Sendo, portanto, orientada pelo seu valor patrimonial, pelo rigor técnico disciplinar do campo teórico da restauração e pela 
prevalência da historicidade da preexistência, não necessariamente se restringindo à ação na matéria original do bem. Se a operação implica na proposição de uma nova arquitetura, por exemplo, em que o ímpeto pela novidade (comum aos interesses da indústria cultural) prevalece sobre a preexistência, ela se distancia do que seria o restauro, mesmo que, em seu próprio contexto, possa ter qualidade.

De fato, a dificuldade de se consolidar esse entendimento contemporâneo se deve, em parte, à percepção de que existem diferentes escalas de interesse cultural do patrimônio, conforme a reflexão de Viñas (2003). Ademais, essa condição ganha ainda mais complexidade em função da própria ampliação da compreensão do patrimônio cultural. A esse respeito, Ignasi de Solà-Morales (1998, p. 9, tradução nossa) ressalta que, na cultura contemporânea, há "um indiscutível indício do pluralismo" das formas de percepção do objeto arquitetônico. Uma das evidências dessa multiplicidade é a ênfase da visualização na apreensão do patrimônio arquitetônico. "O processo de substituição da realidade pelas suas imagens e o modo de ver os monumentos e os lugares, tende igualmente a dissolver-se num imaginário [...]." Um "efeito parque temático" que reúne a realidade e representações dela, e que tende a "[...] validar posições abertas, multissignificativas, inclusive experimentais no tratamento do património construído." Posições que reconhecem o encontro e a interpretação do indivíduo com o bem, mesmo que esse seja mediado por ferramentas que geram consumo cultural. (SOLÀ-MORALES, 1998, p. 9-10, tradução nossa).

Por meio dessa relação contemporânea que se estabelece com o patrimônio por meio de seu restauro, Solà-Morales (2006, p.35) assume que a ação no patrimônio visando sua preservação pode ser identificada por um termo mais recente - intervenção. A intervenção é um processo de percepção complexo e sensível do objeto arquitetônico histórico, cuja chave metodológica é a interpretação profunda e global da preexistência. O objeto é abordado fisicamente relacionando-se "visual e espacialmente com ele, confrontando diferenças e semelhanças, identificando características dominantes e repetições, associações, etc. O problema da intervenção no bem é um constante desafio de interpretação de uma obra de arquitetura já existente, e de um "novo discurso" que essa passa a produzir com a intervenção. Ou seja, a intervenção é a soma das significações que se referem à proposta formal preexistente, aos valores que lhe são atribuídos ao longo do tempo e à intencionalidade promovida com a intervenção.

Em função dessas definições, se estabelece que a intervenção contemporânea no patrimônio arquitetônico não se abstém das relações experimentais mediadas pela indústria. Além disso, ela abarca a compreensão mais ampla da "Restauração" de Viñas (2003) e do restauro de Carbonara $(1998$, 2012), como uma operação que deve visar o rigor teórico e não se limitar à matéria do bem.

\section{A indústria cultural na intervenção contemporânea no patrimônio arquitetônico}

A indústria cultural no Brasil, no que se refere ao patrimônio arquitetônico, tem algumas características diversas das disseminadas globalmente, embora empregue o mesmo modelo adotado na Europa e no resto do mundo. Modelo que é baseado na associação da indústria cultural com o capital imobiliário, promovendo desenvolvimento por meio da valorização de áreas degradadas e da atração de empreendedores. Portanto, 
que engloba os centros históricos urbanos e, por fim, a arquitetura histórica em um processo de "enobrecimento" pelo consumo do patrimônio no turismo cultural da "cidade empreendimento". Essa é a paisagem urbana discutida por Sharon Zukin (2000) e por Otília Arantes (2002, p. 51) que, por sua vez, a identifica como a "cidadeempresa-cultural".

Esse modelo normalmente opera com projetos de maior porte e, segundo Arantes (2002, p. 61), também abarca grandes equipamentos culturais (museus, centros culturais, etc.) que podem ser edifícios históricos. É uma ação estrategicamente planejada, viabilizada pelos meios "persuasivos da cultura arquitetônica da imagem", na qual essa arquitetura emblemática é a "isca ou imagem publicitária" que compõe um espetáculo de alto valor agregado voltado para o exterior (ARANTES, 2002, p. 29).

De fato, a mobilização promovida pela indústria cultural é, de maneira geral, destinada a uma classe com potencial de consumo, e a preservação de grandes equipamentos culturais históricos se relaciona com essa perspectiva de consumo cultural do patrimônio arquitetônico, que promove e é promovido sob o signo fetichista do "status". Contudo, a classe social que consome o patrimônio enobrecido das áreas antigas da cidade não é hegemônica, segundo Silvana Rubino (2009). A autora destaca o estudo de Criekingen (que foca também o Brasil), o qual afirma que essa classe não é rica, e sim mais abastada e escolarizada do que a população local que é deslocada com o enobrecimento das áreas degradas. (CRIEKINGEN, 2006, apud RUBINO, 2009).

Com efeito, Arantes (2002) ressalta que como esse modelo promove acentuada valorização imobiliária, e como frequentemente não confere condições para que os habitantes locais se mantenham no lugar, ele resulta em um processo de expulsão dessa população, pois nessas condições, o valor de uso da habitação é trocado pelo benefício econômico. Diante disso, tal modelo acaba por envolver um alto custo social que pode ser agravado por outras perdas, como o enfraquecimento ou a eliminação da prática social do patrimônio do grupo que é deslocado de seu território.

Marcia Sant'Anna (2004) estuda a aplicação desse modelo no âmbito nacional e afirma que as ações mobilizadas pela indústria cultural (nas cidades de Salvador, Rio de Janeiro e São Paulo a partir da década de 90) foram conduzidas como empreendimentos, empregando formas sistêmicas de gestão e de desenvolvimento nas esferas econômicas e administrativas. Todavia, a autora reforça que o problema desse panorama não é submeter o patrimônio às estratégias de mercado, mas sim submetê-lo completamente a elas. Essa dinâmica de produção da indústria cultural ameaça a função social do patrimônio cultural, sobretudo, quando as ações não são conduzidas por órgãos de preservação e tal como foram realizadas, por "[...] instâncias responsáveis por programas de desenvolvimento econômico, execução de obras públicas, urbanização e habitação." (SANT'ANNA, 2004, p. 330).

Diante disso, observa-se que o modelo globalizado da indústria cultural pode ter resultados diversos, inclusive, cabe apontar a própria insustentabilidade do desenvolvimento e, consequentemente, a degradação do patrimônio que sofreu intervenção. As causas disso podem ser várias. Pode-se ponderar que o desenvolvimento viabilizado, por exemplo, pelo consumo do patrimônio nesse modelo aplicado à nossa realidade, não é garantido somente ampliando-se os investimentos na preservação 
do patrimônio arquitetônico, pois isso não necessariamente cria um consumidor cultural. Como visto, a ação da indústria cultural nesse setor não é direcionada para o consumo de grupos sociais mais populares, nem necessariamente dos economicamente privilegiados. Ela é mais atenta aos grupos que são mais escolarizados e que têm poder aquisitivo suficiente para que haja a identificação com o consumo do patrimônio. Além disso, a abrangência desse modelo aqui costuma ser restrita, uma vez que as cidades empresa-culturais têm sido ações concentradas e desigualmente distribuídas no território nacional. Portanto, para mudar essa conjuntura específica, é preciso primordialmente que haja políticas sociais que promovam incremento de renda e educação, até mesmo para se aumentar a participação dos grupos sociais nesse processo, de modo a "negociar" e a "intermediar" o impacto da indústria cultural para a preservação do patrimônio arquitetônico nessa conjuntura.

\section{Dissonâncias da indústria cultural}

A indústria cultural influencia a intervenção no patrimônio arquitetônico imprimindoIhe características, que podem ser apontadas como dissonâncias. O fachadismo e a museificação são duas delas. A museificação da arquitetura, tal como Ignasi de SolàMorales (1998, p. 6, tradução nossa) caracteriza, ocorre na contemporaneidade quando se sujeita o monumento ao mesmo processo de exposição empregado nos museus, o qual desprende os objetos de seu substrato cultural original, descontextualizando-os e transformando-os tão somente em "imagens". Essa condição, para o autor, "[...] fatalmente produzirá o seu desaparecimento enquanto objetos ligados às situações e significados concretos."

O fachadismo, por sua vez, ocorre quando se despe internamente o patrimônio arquitetônico de sua tipologia histórica, de suas características espaciais, materiais e mesmo estilísticas. Beatriz Kühl (2008) se posiciona contrariamente a essa postura:

Se não se preserva o edifício como um todo, interior e exterior, que não são coisas desconexas, perde-se tudo isso. Destroem-se dados históricos relevantes e deixa-se a obra esvaziada de sua capacidade de funcionar como efetivo suporte material do conhecimento e da memória. (KÜHL, 2008, p. 217)

No entanto, o fachadismo é recorrente em intervenções em nossa realidade. Ele é assumido no contexto de condutas menos exigentes e, por conseguinte, menos criteriosas, pertinente às edificações de menor notoriedade ou representatividade, protegidas principalmente como elementos de conjuntos históricos urbanos, visando a preservação da ambiência urbana. Essa conduta, embora corroborada por órgãos de preservação (pois normalmente se vincula ao nível de proteção), implica na supressão das referências históricas no interior das edificações, conforme citado. Assim, a repercussão de tal condição pode afetar a significação desse patrimônio, no que se refere às relações dos grupos sociais com o edifício e com o território em que esse se encontra. Um exemplo disso é o que ocorre quando são acrescidos novos pavimentos ao interior das edificações em sítios urbanos. Esse adensamento promove uma mudança de como se usa o bem, que repercute nas práticas sociais em relação à edificação e ao espaço público contíguo. 
Cabe, então, ponderar que o patrimônio arquitetônico, representado por edificações isoladas de menor porte e por edificações que compõem os conjuntos históricos urbanos, pode ser mais sujeito ao fachadismo do que a arquitetura monumental, até mesmo em função do tipo de proteção, haja vista que aquelas normalmente não são tombadas e essa costuma ser. Por outro lado, as edificações de maior porte podem ser mais sujeitas à "museificação", conforme Solà-Morales (1998, p. 6) entende.

De fato, tanto o fachadismo como a museificação são lapsos da intervenção, de assimilação qualitativa do passado e dos produtos do passado. Essa condição vai ao encontro do consumo superficial e rápido pela imagem e pelo patrimônio estereotipado, que pode tomar o lugar da compreensão teórico-crítica da história da arquitetura e da teoria da restauração.

A imprudência em relação aos monumentos históricos e a seus aspectos documentais, resulta na perda de um valor fundamental, que é diversidade, a multiplicidade. Perda de multiplicidade que nega um preceito que deveria estar presente na vida em geral, que é a tolerância. Preservar apenas aquilo que parece proveitoso a alguns em um dado momento, é a subversão desse preceito. (KÜHL, 2006, p. 35)

A perda da diversidade por supressões infligidas ao bem pode ser apontada como outra dissonância da intervenção característica da influência da indústria cultural. SolàMorales (1998, p. 6, tradução nossa) também identifica perdas quanto à diversidade cultural nesse processo, e acrescenta que a "suspensão" das "particularidades" do bem resulta em "valores transhistóricos", ou seja, valores que perpassam a historicidade do bem e se relacionam com a interculturalidade. Por outro lado, essas características não necessariamente implicam o desaparecimento da significação local do patrimônio arquitetônico, pois, como já definido aqui, não existe uma homogeneização completa e global.

Ainda no âmbito da homogeneização, o uso definido para a intervenção no patrimônio arquitetônico, pode caracterizar-se também como uma dissonância promovida pela indústria cultural. Em verdade, o uso prático do patrimônio arquitetônico é indispensável a sua conservação. Além disso, ele também é uma das principais condições para viabilidade financeira do empreendimento que promove a intervenção, pois o novo uso da arquitetura histórica a insere no tecido social da cidade. Contudo, entender o novo uso proposto ao bem unicamente dessa forma pode resultar em perdas à significação e à integridade desse. O novo uso definido na intervenção deve ser adequado àquele bem, porque o edifício deve atender a um novo programa que não é necessariamente o mesmo para o qual foi criado.

Logo, a questão do uso do patrimônio é mais complexa do que parece de antemão e não pode ser resumida à viabilidade utilitária do bem. Conforme afirma Kühl (2008), o uso é um meio, e não a finalidade da intervenção. Ele deve ser adequado ao bem, e sua compatibildade deve ter em conta as características e significados conferidos à edificação e ao lugar em que esse está inserido.

Patrícia Nahas (2015, p. 231) ressalta que, na Itália, a prática da intervenção no patrimônio prima por identificar qual uso seria o mais adequado àquele bem, "[...] de modo que a sua conservação e restauração impliquem na menor modificação do 
texto original." A autora contrapõe tal condição à prática brasileira. Segundo ela, de maneira geral, a intervenção aqui já parte de um novo uso pré-estabelecido pelo cliente ou pelo proprietário do bem e, por vezes, esse uso é incompatível com as características da edificação histórica.

Nesse contexto, há outro extremo quanto à questão da definição do uso para o patrimônio, que é quando essa não ocorre. Embora pareça claro que a ação direta de intervenção no patrimônio não deve ser executada sem que seu uso seja definido, às vezes, isso ocorre, principalmente quando são intervenções promovidas por iniciativas públicas, premidas por questões políticas. Nesses casos, o novo uso da edificação não é definido, ou é um uso provisório, ou não detalhado, o que incorre em ações genéricas e mal planejadas que geram modificações e novas intervenções.

Na prática de atuações recentes, só vez por outra se verifica maior consciência e sensibilidade nas propostas e nas operações, tanto na escala urbana, quanto em edificações isoladas. O que se observa, em geral, é a absoluta prevalência de critérios ditados pelo uso, para obter maiores lucros, para aparecer nos meios de comunicação, e guiados por interesses setoriais e imediatistas. (KÜHL, 2008, p. 207)

De fato, a "imposição" de usos aos bens pode ser uma estratégia política, por visibilidade e por notoriedade, e também uma estratégia de mercado. Embora ela não seja exclusiva do panorama da indústria cultural, é característica dele. Usos culturais e complementares desses são mobilizados para o consumo, cuja repetição é uma fórmula homogeneizante. Ademais, a dificuldade da manutenção de usos diversificados desestimula o uso habitacional, que contribui para minimizar o custo social do modelo globalizado aplicado aos sítios urbanos. Consequentemente, a carência de democratização dos usos também redunda nos, já citados, custos culturais e políticos infligidos aos grupos sociais.

Outra dissonância das práticas da indústria cultural na intervenção no patrimônio arquitetônico se refere ao novo, no âmbito da adequação do bem ao uso proposto e, por conseguinte, a sua funcionalidade. Essa condição ocorre quando o novo é "imposto" ao bem, normalmente na forma de acréscimo. Entende-se que o novo na intervenção no patrimônio, faz parte do problema a ser criativamente respondido pelo arquiteto, inclusive, o novo nesse processo pode ampliar a significação conferida ao bem, conforme discutido por Paolo Marconi (1993). Contudo, o autor também ressalta que nessa tarefa do arquiteto, a intervenção tem sido mais mobilizada pelo novo do que pelo antigo. Ou seja, o novo que deveria se estabelecer entre a nova funcionalidade e o restauro do patrimônio arquitetônico, tem se sobressaído à preexistência na intervenção, sendo o ambiente típico em que isso ocorre o da indústria cultural. Nesse caso, o acréscimo feito à arquitetura histórica tem como prerrogativas o impacto e a imagem emblemática para o consumo.

Nahas (2015, p. 345) identifica essa dinâmica em intervenções contemporâneas no patrimônio arquitetônico no Brasil (por meio do estudo de obras realizadas nas três últimas décadas). Para a autora, há um conflito contemporâneo da preservação entre "permanência e mudança, antigo e novo", que tem pendido cada vez mais para o protagonismo do novo sobre o antigo, pois, "[...] a conservação deixou de ser o mote principal da ação de 'restauro' e passou a ser uma coadjuvante na intervenção. 
O projeto do novo guia a modificação do antigo com o argumento de 'atualizar' o monumento." (NAHAS, 2015, p. 271). Cabe destacar que, se o novo for deveras necessário à intervenção, a ponto de sua imposição à preexistência ser essencial, é muito provável que tal uso seja incompatível com o bem.

Portanto, o novo, o fachadismo, a museificação, a homogeneização e o uso na prática de intervenção são partes do processo produtivo dicotômico implementado pela indústria cultural, partes de um discurso contemporâneo particular da atual maneira de ver o passado e atuar em sua preservação. Nesse contexto, esses podem ressignificar o bem para novos grupos sociais, todavia, se predominarem sobre a preexistência, eles têm potencial de infligir prejuízos à significação latente conferida ao patrimônio arquitetônico pelos grupos sociais mais próximos a ele.

\section{Considerações finais}

A intervenção no patrimônio arquitetônico é contextualizada ao panorama sociocultural, mas também econômico e político. Ela é um empreendimento que pretende preservar a significação e a integridade física do bem, além de conferir-lhe funcionalidade, por meio de um exercício criativo e respeitoso do autor. Portanto, a intervenção deve ser atenta à "nova ordem cultural", observando as várias escalas de significação e experimentação que ocorrem por intermédio do patrimônio, reconhecendo-as e legitimando-as como programas de alcances e demandas complementares. Sendo assim, a intervenção pode, ou por vezes precisa, produzir imagens e/ou experiências, além de preservar a historicidade e a significação. Logo, a intervenção no patrimônio arquitetônico, baseada na significação desse, também pode ressignificá-lo.

Todavia, se a intervenção promove um novo discurso que minimiza ou ignora o discurso preexistente (da arquitetura histórica), esse se torna uma narrativa coadjuvante. E, se a parte da significação do bem que lhe confere diversidade (seus valores e significados locais ou regionais) não é prioritária, o discurso que, então, se promove tende a ser comum (homogeneizado). Ademais, se o discurso da intervenção não é baseado nos significados da preexistência, ele é incoerente em relação ao seu processo metodológico de desenvolvimento estabelecido no campo disciplinar teórico da restauração.

Diante disso, conclui-se que na intervenção contemporânea, um parâmetro que pode verificar a preservação da condição do patrimônio arquitetônico como referência histórica é o discurso produzido por ela. Se esse é preponderantemente o discurso da preexistência, ele é coerente em relação ao referencial teórico-conceitual do campo disciplinar da restauração. Mas, se a intervenção promove um novo discurso que prevalece sobre o da preexistência, esse é um discurso superficial ou mesmo incoerente em relação ao referencial teórico da restauração e tende a comprometer o patrimônio como referência histórica. Outrossim, esse discurso superficial ou incoerente é um discurso típico da indústria cultural (midiático voltado para o consumo).

Sendo assim, pode-se ponderar que a intervenção condicionada pela indústria cultural fomenta e consolida o distanciamento entre o campo disciplinar teórico e a prática da intervenção, à medida que se afasta da significação dos grupos locais/regionais que deve ser a base do processo metodológico da intervenção. Não obstante, o comprometimento do bem como referência histórica, por meio da minimização do 
discurso da preexistência, acaba por ser uma velada negação do reconhecimento da autoconsciência dos grupos sociais mais íntimos ao bem.

Com efeito, a indústria cultural tem potenciais positivos e negativos. Ela impacta no processo de intervenção no patrimônio arquitetônico, configurando uma dinâmica que apresenta vários desafios que vão além das dificuldades estruturais inerentes ao próprio processo de intervenção, pois a minimização dos impactos negativos depende primordialmente de igualdade estrutural de condições socioculturais e também econômicas, para que os grupos sociais busquem a "diferença" em meio à expansão da indústria cultural. Por sua vez, a intervenção no patrimônio arquitetônico no Brasil envolve todas essas questões e ainda outras, mas uma precisa ser reforçada: a de que os grupos sociais ainda encontram dificuldades para serem reconhecidos nesse processo, como consumidores de cultura e também como produtores autoconscientes dela.

\section{Referências bibliográficas}

ARANTES, O. B. F. Uma estratégia fatal. A cultura das novas gestões urbanas. In: ARANTES, O. B. F.; VAINER, C.; MARICATO, E. (Org.). A cidade do pensamento único: Desmanchando consensos. 3. ed. Petrópolis: Vozes, 2002.

CANCLINI, N. G. O patrimonio cultural e a Construcao Imaginaria do Nacional. Revista de Patrimônio Histórico e Artístico Nacional, v. 2, n. 23, p. 95-115, 1994. Disponível em: <http:// bit.ly/2JG1bUu>. Acesso em: 10 maio 2019.

. A globalização imaginada. 1. reimp. ed. São Paulo: Editora lluminuras Ltda, 2007.

Consumidores e cidadãos: conflitos multiculturais da globalização. 8. ed. Rio de Janeiro: Editora UFRJ, 2010.

CARBONARA, G. Tendencias actuales de la Restauración en Italia. Loggia, Arquitectura \& Restauración, n. 6, p. 12-23, 1998. Disponível em: <https://doi.org/10.4995/loggia.1998.5339>. Acesso em: 10 maio 2019.

An Italian contribution to architectural restoration. Frontiers of Architectural Research, v. 1, n. 1, p. 2-9, 2012. Disponível em: <https://doi.org/10.1016/j.foar.2012.02.007>. Acesso em: 10 maio 2019.

CARTA DE VENECIA. Carta Internacional sobre la Conservación y la Restauración de Monumentos y Sitios. II Congreso Internacional de Arquitectos y Técnicos de Monumentos Históricos. Anais...Veneza: 1964. Disponível em: <https://www.icomos.org/charters/venice_sp.pdf>. Acesso em: 10 maio 2019.

FORTUNA, C.; SILVA, A. S. A cidade do lado da cultura: Espacialidades sociais e modalidades de intermediação social. In: SANTOS, B. de S. (Org.). A globalização e as ciências sociais. 2. ed. São Paulo: Cortez, 2002. p. 439-474.

GONÇALVES, J. R. S. Os limites do patrimônio. In: LIMA FILHO, MANUEL FERREIRA, ECKERT, CORNELIA \& BELTRÃO, J. (Org.). Antropologia e patrimônio cultural: diálogos e desafios contemporâneos. Blumenau: Nova Letra, 2007. p. 239-248.

HARVEY, D. C. Condição pós-moderna: uma pesquisa sobre as origens da mudança cultural. 17. ed. São Paulo: Edições Loyola, 2008.

JAMESON, F. Pós-modernismo: a lógica cultural do capitalismo tardio. 2. ed. [S.I.] Ática, 2000.

KÜHL, B. M. História e ética na conservação e na restauração de monumentos históricos. Revista CPC, v. 1, n. 1, p. 16-40, 2006. Disponível em: <http://bit.ly/2JExinC>. Acesso em: 10 maio 2019. 
KÜHL, B. Preservação do patrimônio arquitetônico da industrialização: problemas teóricos de restauro. 1. reimp. ed. Cotia, SP: Atelie Editorial, 2008

MARCONI, P. I/ restauro e I'architetto. 2. ed. Venezia: Marsilio Editori, 1993.

MENESES, U. T. B. de. O campo do patrimônio cultural: uma revisão de premissas. I Fórum Nacional do Patrimônio Cultural: Sistema Nacional de Patrimônio Cultural : desafios, estratégias e experiências para uma nova gestão, p. 25-39, 2009. Disponível em: <http:// bit.ly/2YTJ7dj>. Acesso em: 10 maio 2019.

NAHAS, P. V. Antigo e novo nas intervenções em preexistências históricas: a experiência brasileira (1980-2010). São Paulo: Tese (Doutorado em Arquitetura e Urbanismo)-Faculdade de arquitetura e urbanismo, Universidade de São Paulo, 2015. Disponível em: <https://doi. org/10.11606/T.16.2016.tde-08032016-151656>. Acesso em: 10 maio 2019.

RUBINO, S. Enobrecimento urbano. In: Plural de cidades: léxicos e culturas urbanas. Coimbra: Edições Almedina, 2009. p. 25-40.

SANT'ANNA, M. A cidade-atração: a norma de preservação de centros urbanos no Brasil dos anos 90. [S.I.] Tese (Doutorado em Arquitetura e Urbanismo), Faculdade de Arquitetura e Urbanismo, Universidade Federal da Bahia, 2004.

SANTOS, B. de S. Seis razões para pensar. Lua Nova: Revista de Cultura e Política, n. 54, p. 13-23, 2001. Disponível em: <http://bit.ly/2YK2xRy>. Acesso em: 10 maio 2019.

A globalização e as ciências sociais. 2. ed. São Paulo: Cortez, 2002.

SOLÀ-MORALES, I. de. Patrimonio arquitectónico o parque temático. DC PAPERS, revista de crítica y teoría de la arquitectura, n. 1, p. 5-11, 1998. Disponível em: <http://bit.ly/2YK2xRy>. Acesso em: 10 maio 2019.

Intervenciones. Barcelona: Gustavo Gili, 2006

VIÑAS, S. M. Teoría contemporánea de la restauración. Madri: Editorial Síntesis, 2003.

ZUKIN, S. Paisagens urbanas pós-modernas: mapeando cultura e poder. In: ARANTES, A. A. (Org.). O espaço da diferença. São Paulo: Campinas: Papirus, 2000. p. 80-103. 